\title{
Mathematical modelling of the landslide occurred at Gagliano Castelferrato (Italy)
}

\author{
M. Maugeri, E. Motta, and E. Raciti \\ Department of Civil and Environmental Engineering, University of Catania, Italy
}

Received: 14 July 2005 - Revised: 20 December 2005 - Accepted: 20 December 2005 - Published: 7 February 2006

Part of Special Issue "Documentation and monitoring of landslides and debris flows for mathematical modelling and design of mitigation measures"

\begin{abstract}
Shallow slopes in clayey colluvial covers are often involved in progressive downhill motion with discontinuous rate of movements, depending on fluctuations in pore-water pressure.

In geotechnical engineering research on natural slopes, the main efforts have been concentrated on stability analysis, always with a rigid perfectly plastic body assumption. In case of slow slope movements, however, the notion of stability losses its sense, so the main question is not to evaluate a stability factor, but to model a velocity field and to define the kinematic and dynamic features of the movement (mobility analysis).

Many authors, in their researches, deal with slow slope movements and for the complexity of the problem and the great number of parameters involved they agree about applying numerical techniques (FEM, FDM) and advanced material modelling (elastoviscoplasticity) and suggest to calibrate the involved parameters values with the help of "back analyses" of existing case histories.

In this paper a mathematical model predicting the landslide body viscous deformations, is presented. The model has been implemented in a computer FDM code, and has been tested on some well known case histories. Here it is applied to the case of a landslide occurred at Gagliano Castelferrato (Sicily - Italy), where a great number of field measurements was available.
\end{abstract}

\section{Introduction}

In geotechnical research, the main efforts in the domain of natural slopes have been concentrated on classical methods of stability analysis, based on a rigid perfectly plastic body assumption and on the individuation of a hypotetical sliding surface. The development of new computational procedures later came to better model the behaviour of soil or rock

Correspondence to: M. Maugeri

(mmaugeri@dica.unict.it) masses introducing advanced material modelling (elastoviscoplasticity).

Damage caused by landslides seems to be closely connected to the rate of movement, the way it is triggered off and develops and the extension of the involved area (Hungr et al., 1984).

Many authors, in their researches, deal with slow slope movements in natural slopes, that represent a typical example of the creep behaviour of soils and rocks (Bertini et al., 1980; Butterfield, 2000; D'Elia, 1991; Feda, 1992; Gottardi et al., 2001; Leroueil et al., 1996; Picarelli, 1997; Russo et al., 1997; Vulliet, 1999). There are different kinds of creep: gravitational creep is gravity dependent, so it is "continuous" and "progressive". Seasonal creep depends primarily on changing climatic conditions: the involved slopes imperceptibly move, alternating low speed of movement periods (just some $\mathrm{mm} / \mathrm{year}$ ) and accelerating phases (even several $\mathrm{m} / \mathrm{day}$ ), in response to fluctuations in pore-water pressure induced by seasonal change in ground water level (Vulliet, 1999).

This paper deals with mathematical modelling of seasonal creep in natural slopes: in this case the notion of stability losses its sense, so the main question is not to evaluate a stability factor, but to model a velocity field and to define the kinematic and dynamic features of the movement (mobility analysis). For the complexity of the problem and the great number of parameters involved relating together geometrical features and constitutive models of soil, most of the quoted authors suggest to apply numerical techniques (FEM, FDM) with advanced material modelling (elastoviscoplasticity) and to calibrate the involved parameters with the help of "back analyses" of existing case histories.

A mathematical model predicting the landslide body viscous deformations, is presented and then implemented in a computer FDM code. This code has been tested on some well known case histories: Alverà Landslide (Deganutti and Gasparetto, 1992; Butterfield, 2000; Gottardi and Butterfield, 2000; Silvano, 2001); Sallédes experimental embankments (Morin, 1979; Blondeau et al., 1983; Pouget et al., 1985; 


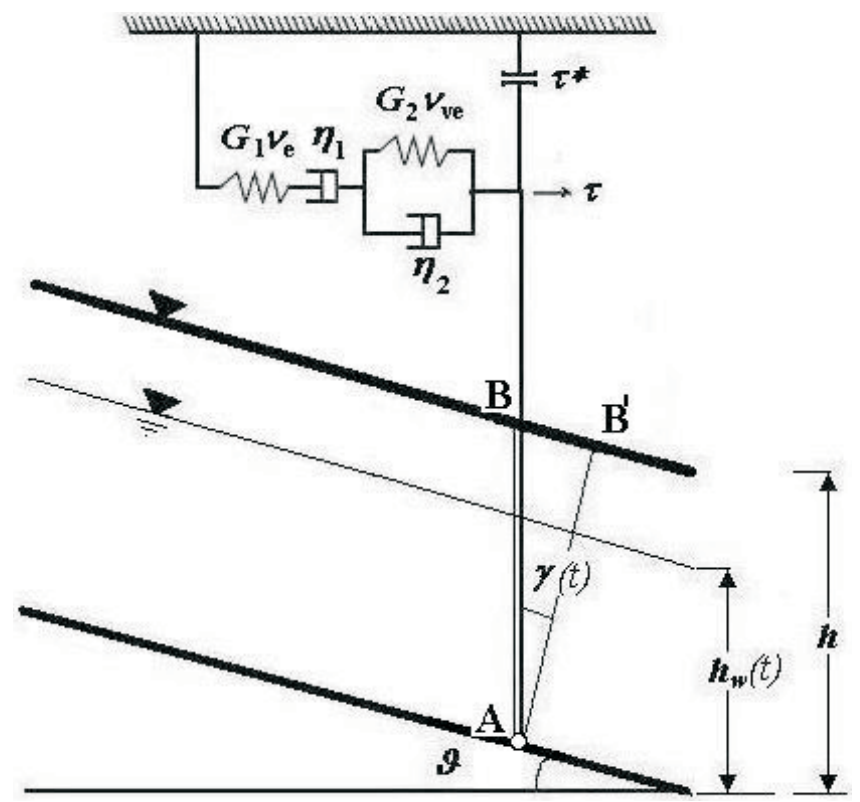

Fig. 1. A single-layer mechanical scheme to evaluate the shear strain inside a sliding slab of soil; $\vartheta$ is the slope angle. $\gamma(t)$ is the rotation of a hypothetical vertical line inside the landslide body, that represents the shear strain; $\tau$ is the shear stress; $h$ is the landslide body vertical thickness; $h_{w}(t)$ is the ground water level, measured from the stable base.

Vulliet, 1986; Cartier et al., 1988; Russo, 1997); Fosso San Martino landslide (Bertini et al., 1980, 1984, 1986; Cazacu and Cristescu, 2000; D'Elia et al., 1983, 1998), but the obtained results are shown elsewhere (Maugeri et al., 2005). Here it will be applied to the case of Gagliano Castelferrato Landslide (Central Sicily - Italy), chosen for the great number of available results of field measurements and inclinometric and piezometric monitoring, from the beginning of 1990 up to the end of 1993 (Raciti, 2003).

\section{A Rheological model for slow slope movements}

Let us hypotize having a slope with a traslative sliding mechanism (Fig. 1). $\vartheta$ is the slope angle; $h$ is the landslide body thickness measured in the vertical direction; $h_{w}(t)$ is the ground water level, measured from the stable base $s_{\text {TOT }}$ will be the total surface displacement measured at the ground level. To evaluate the viscous deformations inside a clayey soil slab in response to an effective stress change an elastovisco-plastic rheological model has been adopted for the clayey material.

In a first approach the all landslide body can be thought as a single layer that can undergo shear strains. An hypothetical vertical line inside the landslide body can be represented as a vertical shelf beam $(\mathrm{AB})$ in which the basal node, $\mathrm{A}$, is partially fixed; the rotation $\gamma(t)$ of the beam $\mathrm{AB}$ around its lower node, A, represents the shear strain (see Fig. 1).
The displacement at the ground level, $s_{\mathrm{TOT}}$, can be calculated by the following equation:

$s_{\mathrm{TOT}}=\gamma(t) \cdot h$

If the landslide body is not homogeneous, or is more than $10 \mathrm{~m}$ thick, a multilayer model can be used, in which the sliding body can be discretised into $n$ layers of appropriate thickness (Fig. 2). In this case, an hypothetical vertical line inside the landslide body can be represented as a vertical shelf beam with a partially fixed basal node and a series of other beams linked to the lower node and linked each other by partially fixed nodes. For each $i$-layer $(1<i<n), \gamma_{i}(t)$ is the rotation of a hypothetical vertical line inside each layer of discretization, that is the shear strain inside each layer. The total shear strain is represented by the profile given by the all the rotations $\gamma_{i}(t)$ of the beams around their lower node (see Fig. 2).

The total surface displacement measured ad the ground level, $s_{\mathrm{TOT}}$, can be calculated by the following equation:

$s_{\text {TOT }}(t)=\sum_{i=1}^{n} \gamma_{i}(t) \cdot h_{i}$

in which, for each $i$-layer, $h_{i}$ is the thickness of the measured in the vertical direction; $s_{i}$ is the relative displacement and it can be calculated as $s_{i}(t)=\gamma_{i}(t) \cdot h_{i}$.

$h_{w}(t)$ is the ground water level, measured in the vertical direction from the stable base.

In Fig. 1, a Burgers model is represented but any springdumper-plastic body in theory can be inserted. In this work nine rheological models have been tested in the numerical application (see Table 1).

The variation of piezometric levels, whose chronological course can be deduced by means of piezometric monitoring, has been taken as the only cause of effective stress boundary condition change (seasonal creep). The mobilizing stress is hypotised as gravitative and coinciding with the weight component acting parallel to the sliding surface, so it can be usually taken as constant. The response in shear strain is evaluated representing the landslide body behaviour, from time to time, by specific rheological elements.

\section{The mathematical model}

\subsection{The single layer model}

A mathematical model, based on Hohanemser and Prager (1932) general equation for visco-elastic behaviour (Reiner, 1958) has been built up to evaluate the shear deformation, $\gamma(t)$, of an hypothetical vertical line of the landslide body. Combining ideally elastic, plastic and viscous bodies equations, the following differential equation can be obtained:

$$
\begin{aligned}
a+ & a_{0} \cdot \tau+a_{1} \cdot \frac{d \tau}{d t}+\ldots+a_{n} \cdot \frac{d^{n} \tau}{d t^{n}}=b_{0} \cdot \gamma+b_{1} \cdot \frac{d \gamma}{d t} \\
& +\ldots+b_{m} \cdot \frac{d^{m} \gamma}{d t^{m}} .
\end{aligned}
$$




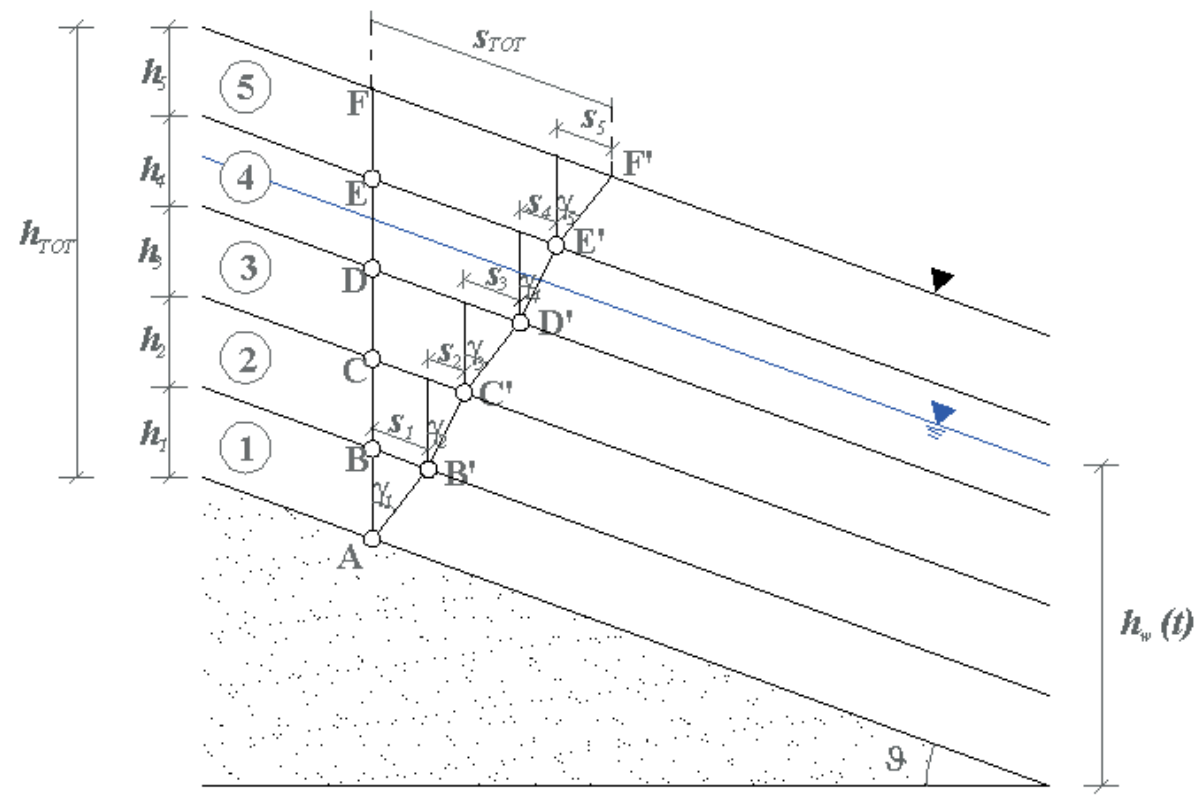

Fig. 2. A multi-layer scheme to evaluate the shear strain inside a sliding slab of soil; $\vartheta$ is the slope angle; $\gamma_{i}(t)$ is the rotation of a hypothetical vertical line inside each layer in which the landslide body has been discretised, and it represents the shear strain. $h_{\text {TOT }}$ is the all landslide body thickness, while $h_{i}$, are the thickness of each $i$-layer, taken in the vertical direction; $h_{w}(t)$ is the ground water level, measured from the stable base. $s_{\text {TOT }}$ is the total surface displacement measured ad the ground level, while $s_{i}(t)$, are the relative displacement measured in correspondence of each $i$-layer and they can be calculated as $s_{i}=h_{i} \gamma_{i}(t)$.

Table 1. Calculation of the values of Eq. (5) parameters.

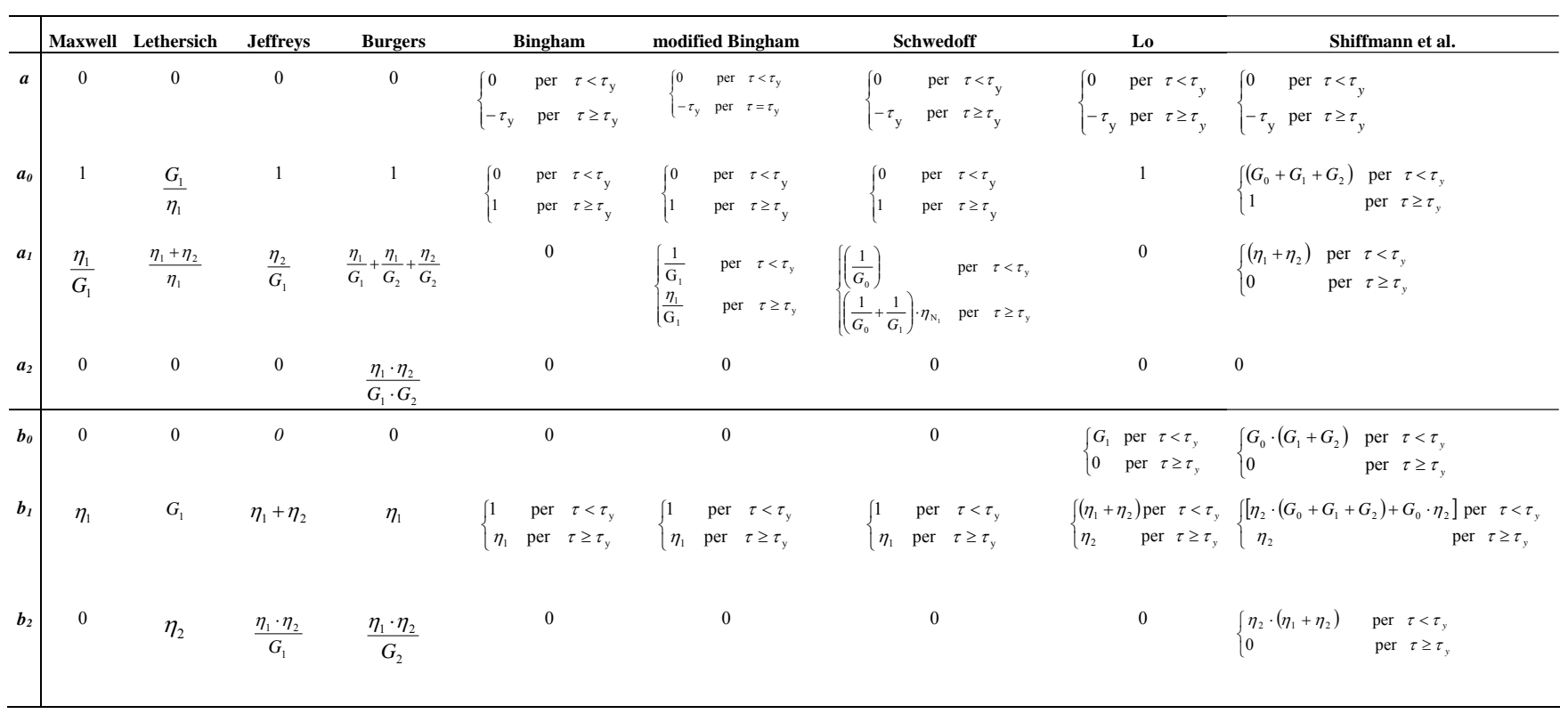

Raciti (2003) used the following second order differential equation:

$$
\begin{aligned}
& a+a_{0} \cdot \tau(t)+a_{1} \cdot \dot{\tau}(t)+a_{2} \cdot \ddot{\tau}(t) \\
& \quad=b_{0} \cdot \gamma(t)+b_{1} \cdot \dot{\gamma}(t)+b_{2} \cdot \ddot{\gamma}(t)
\end{aligned}
$$

where: $a, a_{0}, a_{1}, a_{2}, b_{1}$, and $b_{2}$ are parameters varying in each rheological model. The equations to evaluate them for the nine applied models are listed in Table 1 (Raciti, 2003).

Soil viscosity $\eta_{N}$, expressed in $\mathrm{Pa}^{*}{ }_{s}\left[=N * s / \mathrm{m}^{2}\right]$, can be represented by Newtonian dampers, whose viscosity 
coefficients can be evaluated by Somigliana's equation (1925). In the case of a semi elliptical shaped channel with semi axes $h$ and $b / 2$ Somigliana's equation is as follows:

$$
\eta_{N}=\frac{\gamma_{s} \cdot h^{2} \cdot \operatorname{sen} \vartheta}{2 \cdot\left(v-v_{0}\right) \cdot\left[\frac{h^{2}}{\left(\frac{b}{2}\right)^{2}}+1\right]},
$$

where $\gamma_{S}$, is the soil unit weight; $h, b$ and $\vartheta$, are landslide's thickness taken in vertical, width and slope angle; $v$ and $v_{0}$ are, respectively, the landslide body velocity at the ground surface and near the sliding surface. As in Somigliana's equation only $v$ and $v_{0}$ are considered, without taking into account any kinematic parameter inside the landslide body, the equation fits best with shallow landslides as comparisons to real cases confirm. $\eta_{W}$, is the water viscosity, well known in literature; in this work $\eta_{W}=1 \times 10^{2}$ poise $=10 \mathrm{~Pa}^{*} \mathrm{~s}$ has been assumed (Jaeger, 1964). $G_{0}, G_{1}$ and $G_{2}$ are soil shear moduli; they can be experimentally estimated by laboratory tests or by back analysis. $\tau_{y}$ is the yielding stress. In case of reactivation landslides a value close to the residual shear strength can be chosen.

$\tau(t)$ is the time dependent shear stress and it can be calculated as the non -balanced part of $\tau_{\text {act }}$ (obviously if it is greater than zero):

$\tau(t)=\tau_{\text {act }}-\tau_{\text {lim }}(t)$

$\tau_{\text {act }}$ is the acting stress, hypotised as gravitative and coinciding with the weight component parallel to the sliding surface and taken as constant in each layer, except for the particular case of trenches or overburden (like those of Sallèdes experimental embankments, A e B).

It can be calculated as follows:

$\tau_{\mathrm{act}}=\frac{\sigma}{\cos ^{2} \vartheta} \cdot \operatorname{sen} \vartheta$

in which $\vartheta$ is the slope angle, while $\sigma$ is the total stress, calculated as:

$\sigma=\gamma_{S} \cdot h \cdot \cos ^{2} \vartheta$

in which $h$ is the thickness of the landlide body, measured in the vertical direction.

In many cases of slow slope movements involving colluvial covers, a close correlation between the piezometric levels time evolution and the displacement rates inside the landslide bodies can be observed (Manfredini et al., 1981; Nakamura, 1984; Sangrey et al., 1984; Morgenstern, 1985; Bertini et al., 1986; Cascini et al., 1986; Iverson et al., 1987; Cartier et al., 1988; Sirangelo et al., 1992; Davis et al., 1993; Pouget et al., 1994; Desai et al., 1995; Urciuoli, 1998; Alonso et al., 1999; Russo et al., 1999; Vulliet, 1999; Pellegrino et al., 2000, 2002; Piscitelli et al., 2001; Crosta et al., 2003). So it should be taken into account in the numerical analysis: piezometric level variations during time can be obtained introducing the piezometric level time dependence, $h_{w}(t)$, in the Mohr-Coulomb-Terzaghi criterion used to represent $\tau_{\lim }(t)$, the soil yielding resistance:

$\tau_{\lim }(t)=c^{\prime}+\sigma^{\prime}(t) \cdot \tan \varphi^{\prime}$.

in which $c^{\prime}, \varphi^{\prime}$, are, respectively, the cohesion and the friction angle of each layer of discretizzation and $\sigma^{\prime}(t)$ is the effective stress, which varies with the piezometric level inside the landslide body. This, on its turn, varies with time, $t$ :

$\sigma^{\prime}(t)=\sigma-u(t)$.

where $\sigma$ is the total stress, $u(t)$ is the pore pressure at the base of the layer, and it can be calculated as:

$u(t)=\gamma_{w} \cdot h_{w}(t) \cdot \cos ^{2} \vartheta$

and $h_{w}(t)$ is the ground water level measured from the stable base (it varies during time, $t$ ).

If $\tau(t)>=0$ its value is updated with the calculated one, $\tau(t)=\tau(t)$, otherwise, if the resistant stress get over the effective one, $\tau_{i}(\mathrm{t})=0$ can be taken.

As $\tau(t)$ varies with the piezometric level inside the landslide body, it varies with time.

The viscous behaviour can be found in Eq. (4) parameters.

Equation (4) has been solved by Raciti (2003) with the finite difference method, obtaining the following general parametric equation, whose coefficients are functions of the involved material elasto-visco-plastic features:

$$
\begin{aligned}
\gamma(t & +\Delta t) \\
& =B_{0} \cdot \gamma(t)+B_{(-)} \cdot \gamma(t-\Delta t) \\
& +A+A_{0} \cdot \tau(t)+A_{(-)} \cdot \tau(t-\Delta t) \\
& +A_{(2-)} \cdot \tau(t-2 \Delta t)
\end{aligned}
$$

where:

$$
\begin{aligned}
& B_{0}=\frac{-b_{0} \cdot \Delta t^{2}+b_{1} \cdot \Delta t+2 \cdot b_{2}}{b_{1} \cdot \Delta t+b_{2}} \quad B_{(-)}=-\frac{b_{2}}{b_{1} \cdot \Delta t+b_{2}} \\
& A=\frac{a \cdot \Delta t^{2}}{b_{1} \cdot \Delta t+b_{2}} \quad A_{0}=\frac{a_{0} \cdot \Delta t^{2}+a_{1} \cdot \Delta t+a_{2}}{b_{1} \cdot \Delta t+b_{2}} \\
& A_{(-)}=-\frac{a_{1} \cdot \Delta t+2 \cdot a_{2}}{b_{1} \cdot \Delta t+b_{2}}
\end{aligned}
$$

and $\Delta t$ is the time-step of calculation.

The displacement at the ground surface, $s(t)$, can be calculated by Eq. (1).

In order to achieve an engineering-based validation of the described mathematical model, which well explains the evolution of slow slope movements and to calibrate its parameters, a numerical code, ReoMod, had been compiled, implementing many constitutive models: ReoMod had been applied to the case histories of Alverà Landslide, Sallédes experimental embankments, Fosso San Martino landslide (Raciti, 2003). 
Table 2. Calculation of the values of Eq. (12) parameters.

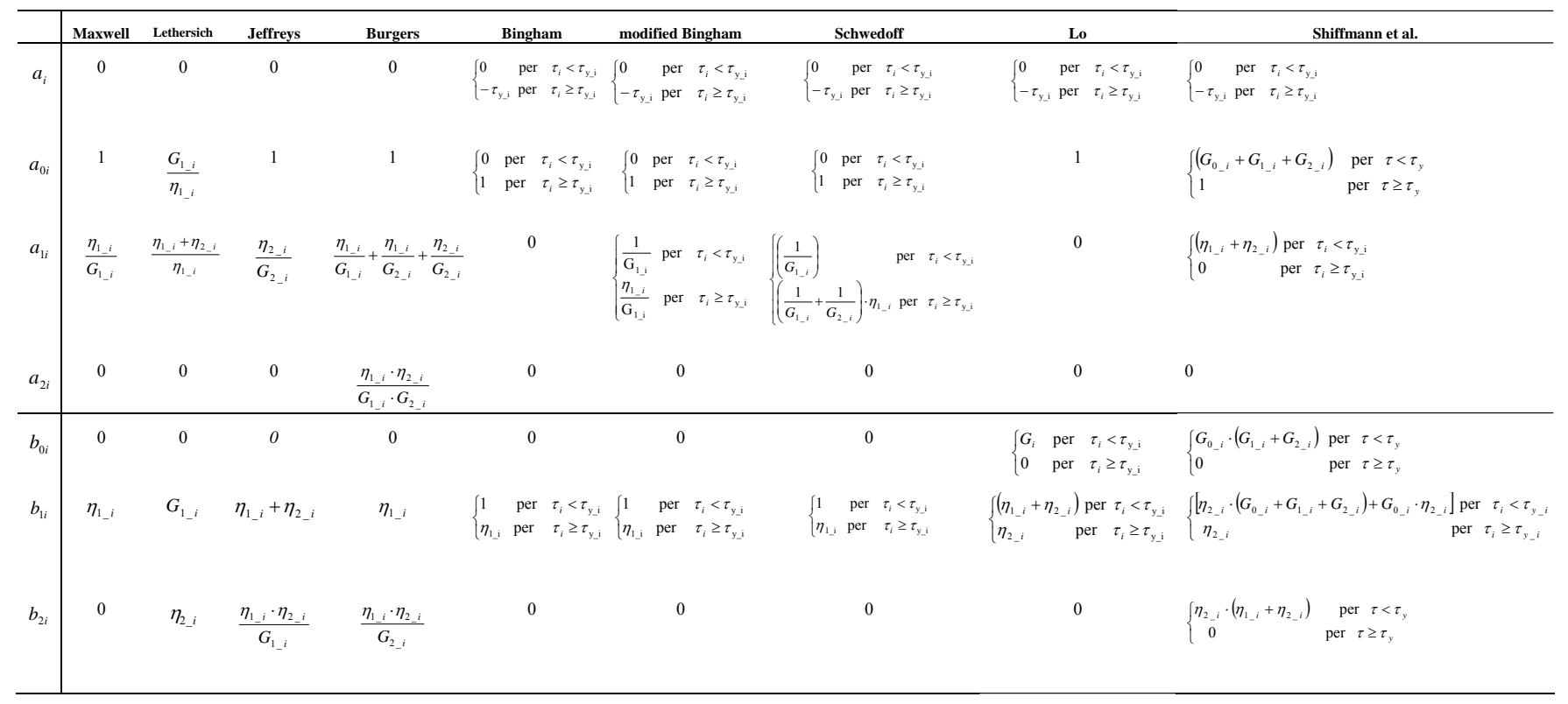

\subsection{The multilayer model}

In the case of a multilayer model, Eq. (4) becomes:

$$
\begin{aligned}
a_{i}+ & a_{0 i} \cdot \tau_{i}(t)+a_{11} \cdot \dot{\tau}_{i}(t)+a_{2 i} \cdot \ddot{\tau}_{i}(t) \\
& =b_{0 i} \cdot \gamma_{i}(t)+b_{1 i} \cdot \dot{\gamma}_{i}(t)+b_{2 i} \cdot \ddot{\gamma}_{i}(t) \quad(1 \leq i \leq n)
\end{aligned}
$$

where $a_{i}, a_{0 i}, a_{1 i}, a_{2 i} ; b_{0 i}, b_{1 i}, b_{2 i}$ are parameters whose values are functions of the mechanical properties of the soil constituting each layer. They are different for each rheological model and they can be evaluated by the equations listed in Table 2.

Soil viscosity coefficients $\eta_{i}\left[\mathrm{~Pa}^{*} \mathrm{~s}\right]$, can be evaluated by Somigliana's equation (1925).

For a better evaluation of the soil slab deformation, as the landslide body has been discretised into thin layers (Fig. 2), a different value of $\eta_{i}$ can be estimated for each layer, taking into account the boundary velocity values, $v_{i}$ and $v_{i-1}$, for each one.

So, for the multilayer model, Somigliana's equation has been written as follows:

$$
\eta_{i}=\frac{\gamma_{s_{-} i} \cdot h_{i}^{2} \cdot \operatorname{sen} \vartheta}{2 \cdot\left(v_{i}-v_{i-1}\right) \cdot\left[\frac{h_{i}^{2}}{\left(\frac{b_{i}}{2}\right)^{2}}+1\right]}, \quad(1<i<n)
$$

where, for each $i$-layer, $\gamma_{s_{-} i}$, is the soil unit weight; $b_{i}$ and $h_{i}$ are layer's thickness taken in the vertical direction and width; $\vartheta$ is the slope angle; $v_{i}$ and $v_{i-1}$ are, respectively, each layer's upper and lower boundary velocities; $\eta_{W}$ is the water viscosity $\left(\eta_{W}=10 \mathrm{~Pa}^{*} \mathrm{~s}\right) . G_{0 \_}, G_{1 \_i}$ and $G_{2 \_i}$ are soil shear moduli inside the $i$-layer; they can be experimentally estimated by laboratory tests on samples of that layer, or by back analysis. $\tau_{y_{-} i}$ is the yielding stress of the $i$-layer. In case of reactivation landslides a value close to the residual shear strength can be chosen.

$\tau_{i}(t)$ is the time dependent shear stress and it can be calculated as the non -balanced part of $\tau_{\text {act } i}(t)$ (obviously if it is greater than zero):

$\tau_{i}(t)=\tau_{\text {act } i}-\tau_{\lim i}(t)$

where $\tau_{\text {act } i}$ is the resulting shear stress, and it can be calculated as follows:

$\tau_{\text {act } i}=\frac{\sigma_{i}}{\cos ^{2} \vartheta} \cdot \operatorname{sen} \vartheta$

in which $\vartheta$ is the slope angle.

$\sigma_{i}=\left[\sum_{m=i}^{n} \gamma_{i} \cdot h_{i}\right] \cdot \cos ^{2} \vartheta$

in which $h_{i}(1<i<n)$ is the thickness of each layer of discretizzation, measured in the vertical direction. $\tau_{\lim i}(t)$ is the yielding shear stress and it can be calculated by the MohrCoulomb-Terzaghi criterion, taking into account the piezometric level time evolution:

$\tau_{\lim _{-} i}(t)=c_{i}^{\prime}+\sigma_{i}^{\prime}(t) \cdot \tan \varphi_{i}^{\prime}$.

in which $c_{i}^{\prime}$ and $\varphi_{i}^{\prime}(1<i<n)$ are respectively, the cohesion and the friction angle of each layer of discretizzation and $\sigma_{i}^{\prime}(t)$ is the effective stress, which varies with the piezometric level inside the landslide body. This, on its turn, varies with time, $t$ :

$\sigma_{i}^{\prime}(t)=\sigma_{i}-u_{i}(t)$. 


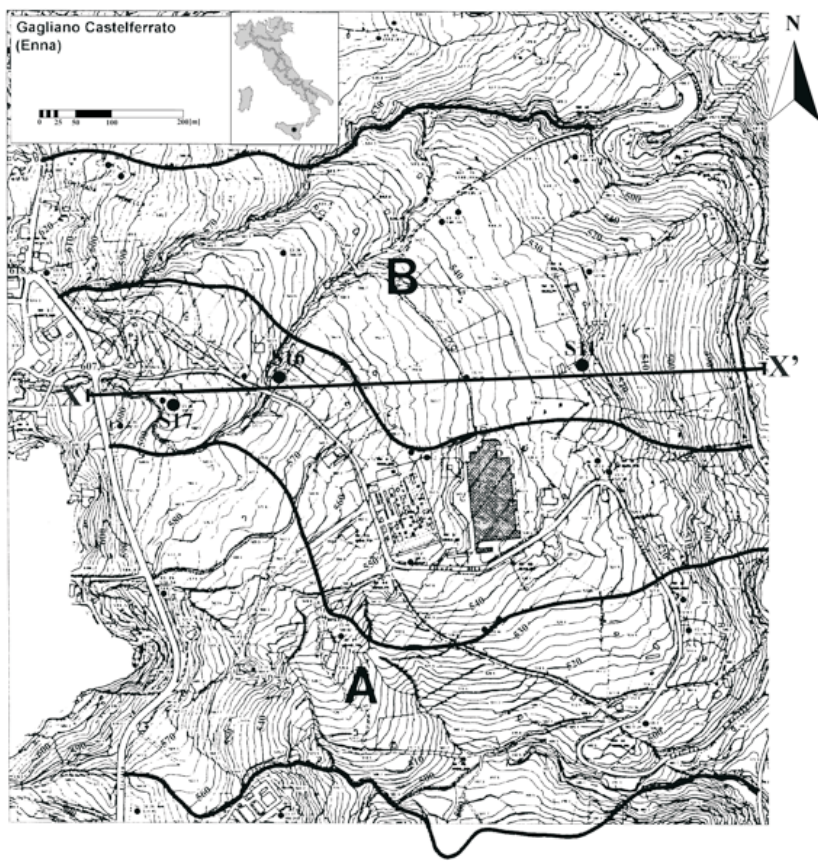

Fig. 3. A Map of Gagliano Castelferrato Landslide area: the northern part of the landslide body, called $\mathrm{B}$, slides toward the north western direction; the southern part of the landslide body, called A, slides toward the south western direction; a transition zone between them moves toward the eastern direction and has more evident deformations at the ground level. XX' is the analysed section, along which S11, S16 and S17 boreholes are located.

where $\sigma_{i}$ is the total stress, $u_{i}(t)$ is the pore pressure measured at the base of each layer, and it can be calculated as follows:

$$
\begin{aligned}
& u_{i}(t)= \\
& \left\{\begin{array}{l}
\gamma_{w} \cdot\left[h_{w}(t)-\sum_{m=1}^{i-1} h_{i}\right] \cdot \cos ^{2} \vartheta \\
\text { if }\left[h_{w}(t)-\sum_{m=1}^{i-1} h_{i}\right]>0 \\
\text { if }\left[h_{w}(t)-\sum_{m=1}^{i-1} h_{i}\right] \leq 0
\end{array}\right.
\end{aligned}
$$

where $h_{w}(t)$ is the ground water level measured from the stable base (it varies during time, $t$ ).

In each layer, if $\tau_{i}(t)>=0$ its value is updated with the calculated one, $\tau_{i}(t)=\tau_{i}(t)$, otherwise, if the resistant stress get over the effective one, $\tau_{i}(t)=0$ can be taken.

As $\tau_{\lim i}(t)$ varies with the piezometric level inside the landslide body, it varies with time.

The system of Eq. (13) can be solved with the finite difference method, obtaining a general parametric system of $n$ equations, whose coefficients are functions of the involved material elasto-visco-plastic features:

$$
\begin{aligned}
& \gamma_{i}(t+\Delta t) \\
& \quad=B_{0 i} \cdot \gamma_{i}(t)+B_{(-) i} \cdot \gamma_{i}(t-\Delta t) \\
& \quad+A_{i}+A_{0 i} \cdot \tau_{i}(t)+A_{(-) i} \cdot \tau_{i}(t-\Delta t)
\end{aligned}
$$
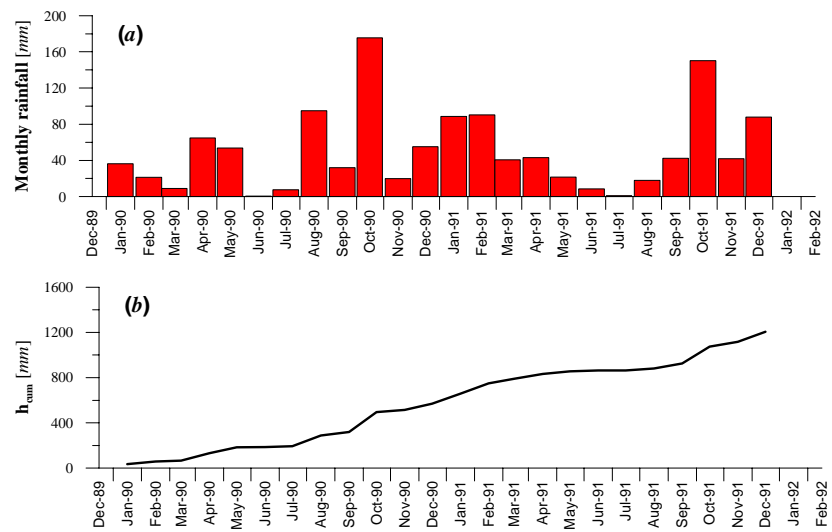

Fig. 4. (a) Histogram of Gagliano Castelferrato monthly rainfall, measured at Gagliano Castelferrato rain gauge (Hydrometric station 192, Gagliano Castelferrato; Elevation m a.s.1. 837), from January 1990 to December 1991. (b) Cumulated rainfall for the same period.
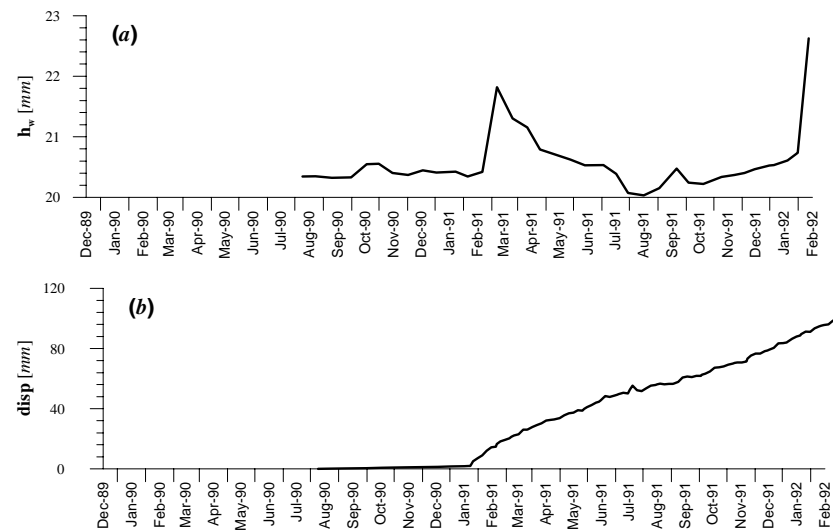

Fig. 5. (a) Piezometric levels measured in S17 borehole from July 1990 to February 1992. (b) Displacements versus time measured in S17 inclinometer, from January 1991 to February 1992.

$$
+A_{(2-) i} \cdot \tau_{i}(t-2 \Delta t)
$$

where:

$$
\begin{aligned}
& B_{0 i}=\frac{-b_{0 i} \cdot \Delta t^{2}+b_{1 i} \cdot \Delta t+2 \cdot b_{2 i}}{b_{1 i} \cdot \Delta t+b_{2 i}} \\
& B_{(-) i}=-\frac{b_{2 i}}{b_{1 i} \cdot \Delta t+b_{2 i}} \\
& A_{i}=\frac{a_{i} \cdot \Delta t^{2}}{b_{1 i} \cdot \Delta t+b_{2 i}} \quad A_{0 i}=\frac{a_{0 i} \cdot \Delta t^{2}+a_{1 i} \cdot \Delta t+a_{2 i}}{b_{1 i} \cdot \Delta t+b_{2 i}} \\
& A_{(-) i}=-\frac{a_{1 i} \cdot \Delta t+2 \cdot a_{2 i}}{b_{1 i} \cdot \Delta t+b_{2 i}}
\end{aligned}
$$

and $\Delta t$ is the time-step of calculation.

As soon as the shear stress $\tau_{i}(t)$ is greater than zero, shear deformations take place, and they can be calculated, for each layer of discretization, by the system of Eq. (21).

In this case, an indication of the ground surface displacement can be obtained by Eq. (2). Obviously, the deformation 


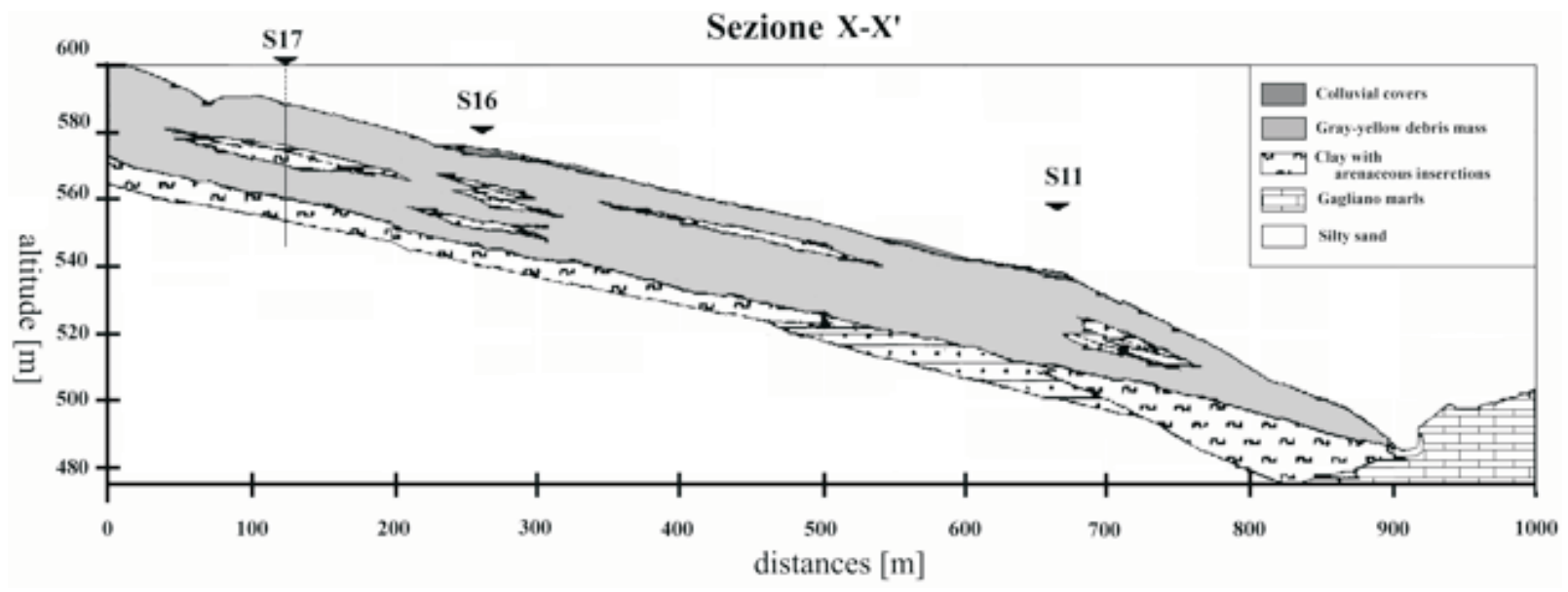

Fig. 6. The geological section $X X$ '.

evolution depends, not only on the actual, but also on the past stress-strain state.

The numerical code ReoMod had been extended for the multy-layer scheme, to solve Eq. (21). Then, to calibrate its parameters, it has been applied to all the case histories quoted in Sect. 3.1, with nine rheological models (Maxwell, Lethersich, Jeffeys, Burgers, Bingham, modified Bingham, Schwedoff, Lo, Shiffmann et al. - in Feda, 1992). The results of these applications are shown elsewere (Maugeri et al., 2005).

\section{Application to Gagliano Castelferrato landslide}

In this paper, a new case history of a landslide occurred at Gagliano Castelferrato (Central Sicily - Italy), has been modeled to verify the viscous behaviour of the landslide body. For this case history, a great number of field measurements and inclinometric and piezometric monitoring was available (Raciti, 2003).

In Fig. 3 a map of the landslide area is shown. The northern part of the landslide body, called B, slides toward the northern-eastern direction; the southern part of the landslide body, called A, slides toward the southern-western direction; a transition zone between them moves toward the eastern direction and has more evident deformations at the ground level.

In Fig. 4a an histogram of Gagliano Castelferrato monthly rainfall, measured at Gagliano Castelferrato rain gauge (Hydrometric station 192, Gagliano Castelferrato; Elevation m a.s.l. 837), from January 1990 to December 1991 is plotted, while Fig. $4 \mathrm{~b}$ shows the cumulated rainfall for the same period.

A field investigation was carried out from 1990 to 1992. Twenty boreholes were executed and piezometric levels were measured from August 1990 to February 1992, while inclinometric deformations were measured from January 1991 to June 1992. Figure 5 deals with the monitoring period: Fig. 5a shows the piezometric level measured in S17 bore- hole from August 1990 to February 1992 and Fig. 5b shows the ground surface displacements, measured very closely to the S17 borehole, versus time from January 1991 to February 1992. Measurements of displacements taken from March to June 1992 are not plotted, as they could not be studied in absence of piezometric level measurements. A close correlation among rainfalls, piezometric levels and rate of movements can be noted, so an influence of pore pressure rising inside the landslide body on the slope movements is evident.

The cross section XX', along which S11, S16 and S17 boreholes are located was chosen for a stability analysis, based on the limit equilibrium method assuming a translational failure mechanism and a rigid plastic behaviour for the soil. Figure 6 shows a plots of the geological cross section XX', while in Fig. 7 the stratigraphy and inclinometric profile in S17 borehole, observed on 30 June 1992, after a period of monitoring started from 1 January 1991, are shown. The sliding surface was located at a depth of about $25-30 \mathrm{~m}$ below the ground surface in the transition zone between the clayey soils ant the silty sands. The stability analysis carried out assuming the different measured piezometric levels, shown that the factor of safety during the observed period sometimes was somewhat less then unity. Consequently some displacements should be observed.

S17 borehole was chosen for the analysis with the numerical code: in Table 3 the input parameters of the model are listed.

Two different analyses were performed: the first using the one-layer model and the second using the multi-layer model, to evaluate the influence of the layers of discretisation number on the analysis results. A depth dependent viscosity was calculated applying Eq. (14), that is a modification of Somigliana's equation. The code applications results, referring to S17 borehole (Figs. 3 and 5), are shown in Figs. 8, 9, 10, 11, 12 and 13 .

The response of the analysis depending on the number of the discretisation layers is shown in Figs. 8 and 9. A comparison between measured and calculated displacement-time sequence with the one-layer and the multilayer scheme (with 5 
Table 3. Input Parameters for ReoMod applications.

\begin{tabular}{|c|c|c|}
\hline & & $\begin{array}{c}\text { Gagliano } \\
\text { Castelferrato } \\
\text { landslide }\end{array}$ \\
\hline \multicolumn{3}{|l|}{ Landslide body geometrical features } \\
\hline Length & $L[m]$ & 890 \\
\hline Width & $l[m]$ & 40 \\
\hline Thickness & $h_{\mathrm{TOT}}[m]$ & 30 \\
\hline Slope angle & $\vartheta\left[^{\circ}\right]$ & 8 \\
\hline \multicolumn{3}{|c|}{ Average soil parameters of the all landslide body } \\
\hline Unit weight & $\gamma_{S}\left[k N / m^{3}\right]$ & 18.90 \\
\hline cohesion & $c^{\prime}\left[k N / m^{2}\right]$ & 20 \\
\hline Peak friction angle & $\varphi_{p}^{\prime}\left[{ }^{\circ}\right]$ & 16 \\
\hline Residual friction angle & $\varphi_{r}^{\prime}\left[{ }^{\circ}\right]$ & $11-12$ \\
\hline \multicolumn{3}{|l|}{ Kinematic parameters } \\
\hline Initial velocity at the ground level & $v[\mathrm{~mm} /$ year $]$ & 82 \\
\hline Initial velocity at the bedrock & $v_{0}[\mathrm{~mm} /$ year $]$ & 0 \\
\hline \multicolumn{3}{|c|}{ Initial average elastic parameters of the all landslide body } \\
\hline Young modulus & $E\left[k N / m^{2}\right]$ & 18000 \\
\hline Poisson's ratio: & $v$ & 0.33 \\
\hline
\end{tabular}

\section{Borehole S17}

INCLINOMETRIC PROFLE I JAN $1991-30$ JUN 1992

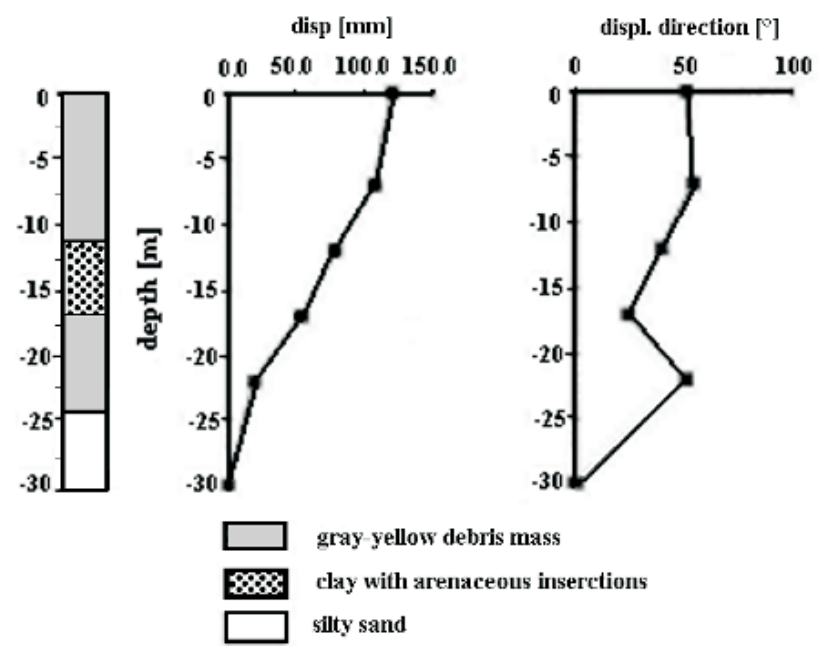

Fig. 7. S17 borehole: stratigraphic condition and inclinometric profile obtained from 1 January 1991 to 30 June 1992.

layers) is presented, using first the Maxwell model (Fig. 8a) and then the Bingham model (Fig. 8b). A comparison between the inclinometric profile and the calculated ones with the one-layer and the multilayer scheme (with 5 layers) are shown, first using Maxwell model (Fig. 9a) and then Bingham model (Fig. 9b). Obviously the comparison confirms that the more is the number of discretisation layers adopted, the more accurate are the results obtained.
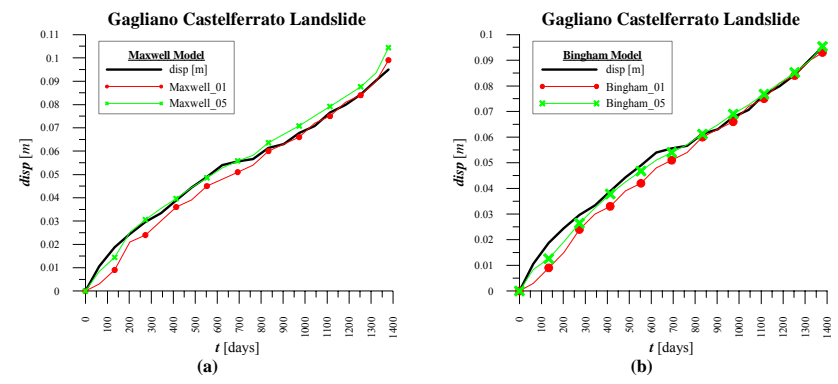

Fig. 8. Comparison between the inclinometric displacement-time sequence measured in S17 borehole and the calculated ones with the one-layer and the multilayer scheme (with 5 layers) (a Maxwell model, b Bingham model).

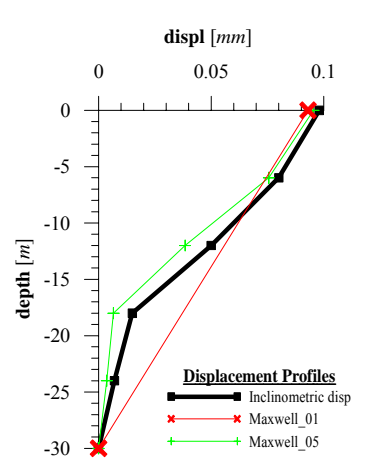

(a)

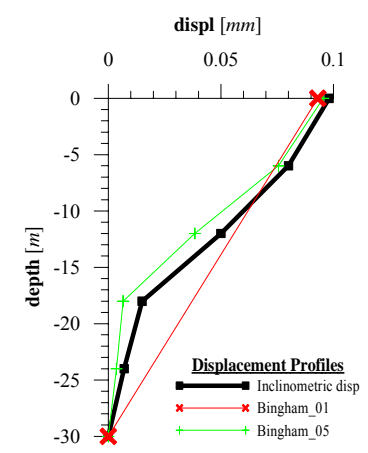

(b)
Fig. 9. Gagliano Castelferrato Landslide: Displacement profiles in S17 borehole: comparison between the measured inclinometric profile and the calculated ones with the one-layer and the multilayer scheme (with 5 layers) (a Maxwell model, b Bingham model).

A further evaluation of the influence of the number of discretisation layers, as well as of the chosen rheological model is presented in Figs. 10, 11, 12 and 13. A comparison, for all the rheological models used in this paper, between the ground displacement-time sequence measured in S17 borehole and the ReoMod ones with the one-layer scheme (Fig. 10) and the multilayer scheme (with 5 layers) (Fig. 11) is shown.

In Figs. 12 and 13, respectively, a comparison between the calculated profiles for the one-layer and the multilayer scheme (with 5 layers) with the inclinometric profile are presented.

In the analyses Maxwell, Burgers, Lethersich, Jeffreys, Bingham, Modified Bingham, Schwedoff, Lo, Shiffmann, Vyalov models were applied.

In this case history Maxwell, Burgers, Lethersich, Jeffreys, Bingham, modified Bingham, Schwedoff, Lo models provided reliable results, with a good agreement between calculated and measured displacements. However Shiffmann and Vyalov models seems to overestimate the displacement profiles. It is evident that the multilayer scheme grants a more accurate calculated profile, than the singlelayer scheme, however the displacements calculated at the ground surface are almost similar. 


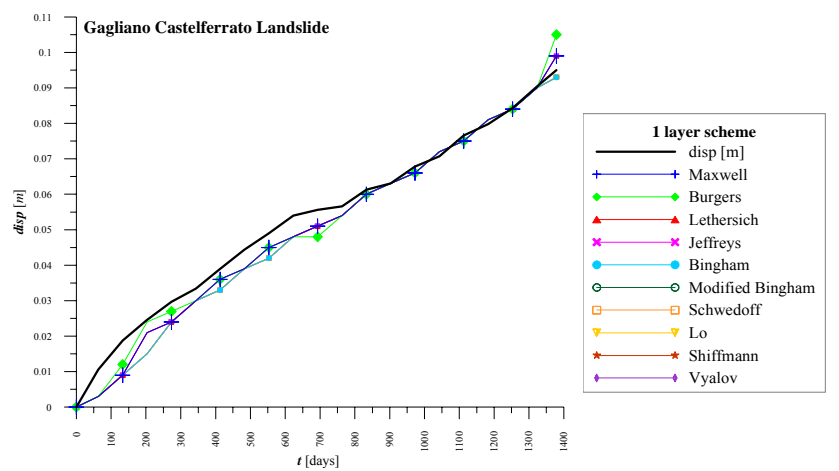

Fig. 10. Comparison between the inclinometric displacement-time sequence measured in S17 borehole and the calculated ones with the one-layer scheme, with the models listed in legend.

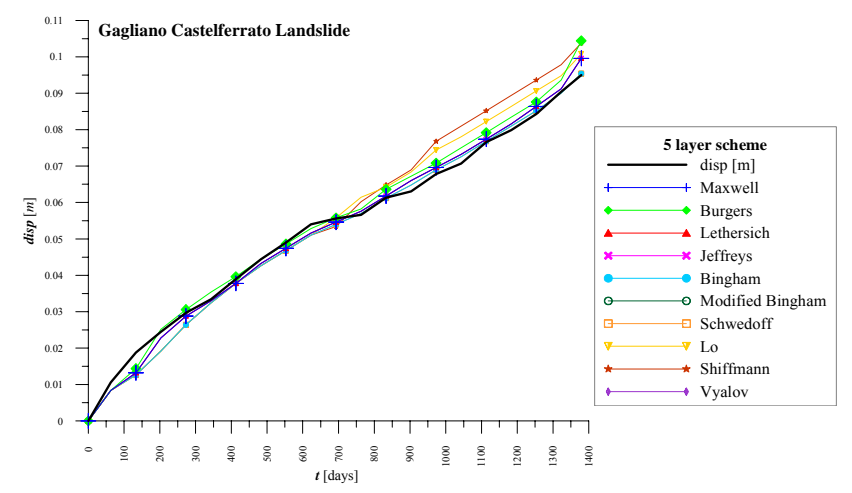

Fig. 11. Comparison between the inclinometric displacement-time sequence measured in S17 borehole and the calculated ones with the multilayer scheme (with 5 layers), with the models listed in legend.

\section{Conclusions}

A numerical model based on the elastoviscoplastic behaviour of the landslide body and on the influence of the piezometric level on the movement rates has been presented.

As in many cases of slow slope movements a close correlation between rising in the piezometric levels and displacement rates of the slope can be observed, it seemed appropriate to assume that the change in effective stress due to pore pressure variations can be one of the main causes of slope deformations. The piezometric level variations during time can be obtained introducing a time dependence of piezometric level, respectively, in Eq. (6) and in Eq. (15), according to experimental measurements. This allows to perform a deformation-time-dependent analysis.

A single-layer and a multilayer mechanical scheme have been presented to predict the deformation evolution of a hypothetical vertical line inside a slope due to increasing of instabilising forces and/or reducing shear strengths for pore pressure rising. A computer code based on a FDM development of Eq. (15), valid both for the one-layer and for the multy layer scheme, was compiled to this aim. Several constitutive laws have been implemented in the numerical code

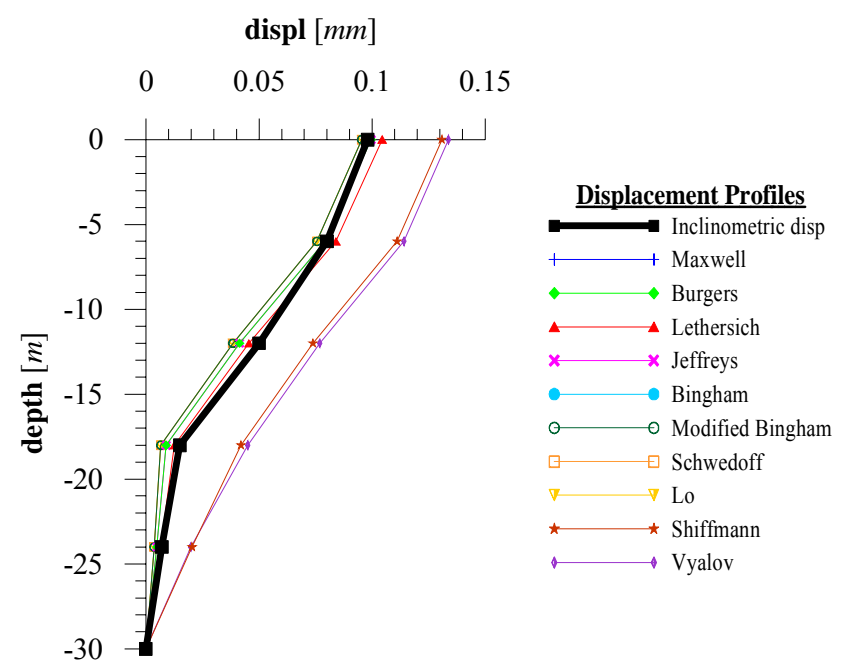

Fig. 12. Gagliano Castelferrato Landslide: displacement profiles. Comparison between the inclinometric profile measured in S17 borehole and the calculated ones with the one-layer scheme, with the models listed in legend.

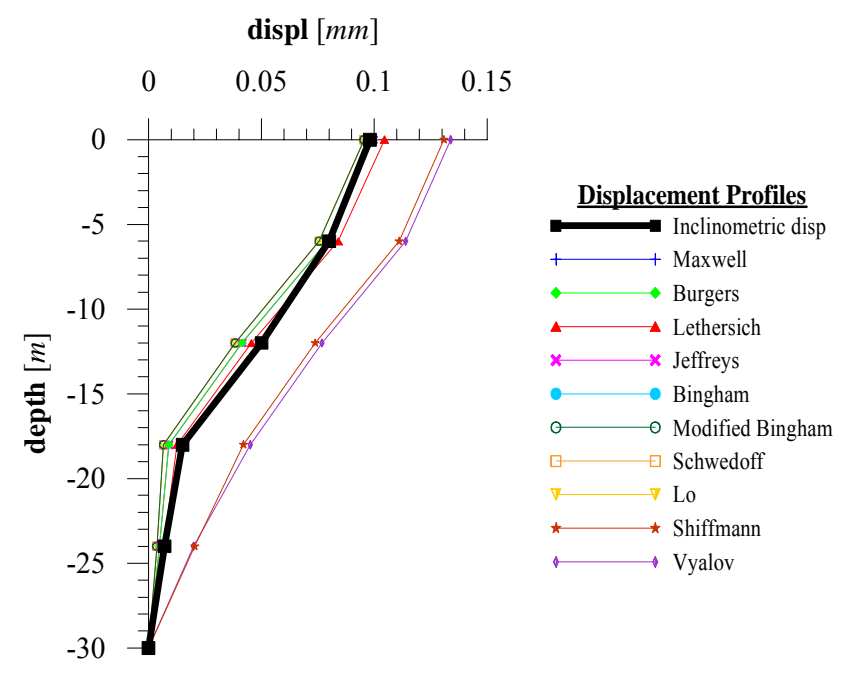

Fig. 13. Gagliano Castelferrato Landslide: displacement profiles. Comparison between the inclinometric profile measured in S17 borehole and the calculated ones with the multilayer scheme (with 5 layers), with the models listed in legend.

to represent the soil behaviour: the applications presented in this paper are those based on Maxwell, Lethersich, Jeffreys, Burger, Bingham, modified Bingham, Lo, Shiffmann and Vyalov rheological models.

The viscosity of the landslide body has been evaluated by Somigliana's equation. This equation, in the original form, usually fits best with shallow landslides, as it takes into account just the soil mass rate at the sliding surface and at the ground surface. To obtain a better evaluation of the deformation of an hypothetical vertical line, in the multilayer model, Somigliana's equation has been adapted calculating a different viscosity value for each layer of discretisation, 
substituting the soil rates at the sliding surface and at the ground level, respectively with those of the lower and the upper boundary of the $i$-layer, of discretisation. The displacement profiles calculated with this assumption fit best with the inclinometric one: this confirm that more reliable results can be obtained in this way.

In this paper, the presented numerical model has been applied to the case of Gagliano Castelferrato landslide (Sicily - Italy). The change in effective stress due to pore pressure variations was assumed as the main cause of deformationtime evolutions, as the monitoring results evidenced a close correlation between the piezometric levels time evolution and the displacement rates of the slope. A time dependence of piezometric level was introduced, respectively, in Eq. (6) and in Eq. (15), according to experimental measurements. This allowed to perform a deformation-time-dependent analysis.

The analysis on Gagliano Castelferrato landslide was firstly carried out discretising the landslide body into one layer, then into 5 layers and a depth depending viscosity was evaluated, basing on Eq. (14). Among the implemented constitutive models, Maxwell, Lethersich, Burger, Jeffreys Bingham, modified Bingham, Lo models provide results in a very close agreement with the experimental measures, while Shiffmann and Vyalov models, give higher displacement values.

The results of the analysis show that the hypotheses of the elasto-visco-plastic behaviour of the landslide body and of the influence of the piezometric level on the movements rates were reasonable and that, if the soil parameters are chosen properly, a simple single layer scheme, based on the soil elastoviscoplastic behaviour, can be satisfactory for a prevision of the evolution of displacements at the ground surface but, obviously, a multylayer analysis fits best in representing both the ground level displacements and the vertical profiles deformation evolutions, and this would be even more evident if a non-homogeneous or very thick landslide body should be modelled.

When analysing a natural slope, it would be advisable to investigate not only on its stability, basing on the limit equilibrium method and on a rigid plastic soil behaviour, but also on its kinematic features, and on the probable evolutions of the movements during the landslide lifetime. Such a kind of analysis should be based on deformation-time dependent models, that is on the assumption of an elasto-visco-plastic behaviour of the soil.

The presented mathematical model, can be applied to predict the future evolution of the slope movement driven on by seasonal fluctuating groundwater level, after carrying out a proper calibration of soil parameters by a back analysis of available field measurements.

Acknowledgements. The Authors wish to thank F. G. L. Paternò (Eng.) for his help during the surveys in the landslide area and S. D. Accardi for his contribution in the numerical applications.

Edited by: L. Marchi

Reviewed by: One referee

\section{References}

Alonso, E. E., Lloret, A., and Romero, E.: Rainfall induced deformations of road embankments, Italian Geotechnical Journal XXXIII, 1, 71-76, 1999.

Bertini, T., Cugusi, E., D'Elia, B., and Rossi-Doria, M.: Lenti Movimenti di Versante nell'Abruzzo Adriatico: caratteri e criteri di stabilizzazione, Proc. XVI Convegno Nazionale Di Geotecnica, Bologna, 1, 91-100, 1986.

Bertini, T., D’Elia, B., Grisolia, M., Oliviero, S., and Rossi-Doria, M.: Lenti Movimenti di Coltri Colluviali sulle Argille Marnose della Formazione della Laga, Proc XIV Conv. Naz. di Geotecnica, Firenze, II, 207-218, 1980.

Bozzano, F. and Floris, M.: An Interpretation of Slope Dynamics in Pisticci (Southern Italy), Landslides in research, theory and practice, Thomas Telford, London, 2000.

Butterfield, R.: A Dynamic Model Of Shallow Slope Motion Driven by Fluctuating Ground Water Level, Department of Civil and Environmental Engineering, University of Southampton, UK, VIII Int. Symp. On Landslide (1), pp. 203-208, Cardiff (UK), 2000.

Cartier, G. and Pouget, P.: Etude Du Comportement Avent Rupture D'un Remblai Construit Construit Sur Un Versant Instable: Le Remblai De Sallèdes (Puy-De-Dôme), Rapport De Recherche LCPC N ${ }^{\circ}$ 153, Paris, France, 1988.

Cascini, L. and Versace, P.: Eventi pluviometrici e Movimenti Franosi, Atti del XVI Convegno Nazionale di Geotecnica, Bologna, 1986.

Cazacu, O. and Cristescu, N. D.: Constitutive Model And Analysis of Creep Flow of Natural Slopes, Italian Geotechnical Journal, XXXIV, N. 3, pp. 44-54, 2000.

Crosta, G. B. and Agliardi, F.: Failure forecast for large rock slides by surface displacement measurements, Can. Geotech. J., 40, 176-191, 2003.

Davis, R. O., Desai, C. S., and Smith, N. R.: Stability Of Motions Of Translational Landslides, J. Geotechn. Eng., ASCE vol. 119, $\mathrm{n}^{\circ} 3$, pp. 420-432, 1993.

Deganutti, A. and Gasparetto, P.: Some aspects of mudslide in Cortina, Italy, Proc. VI Int. Symp. on Landslides, vol. 1, pp. 373 378, Chrischurch, NZ, 1992.

D'Elia, B.: Deformation Problems In The Italian Structurally Complex Clay Soils, 10th European Conf. On Soil Mechanics And Found. Engrg., Florence, 4, pp. 1159-1170, 1991.

D’Elia, B., Bertini, T., and Rossi-Doria, M.: Colate e Movimenti Lenti, Geologia Applicata e Idrogeologia, vol. XVIII, Parte III, 1983.

Desai, C. S., Samtani, A., and Vulliet, L.: Constitutive Modeling And Analysis Of Creeping Slopes, J. Geotech. Eng., ASCE vol. CXXI, No. 1, January, pp. 43-56, 1995.

Feda, J.: Creep Of Soils And Related Phenomena, Developments In Geotechnical Engineering, 68, Elsevier Amsterdam - London New York - Tokyo, 1992.

Gottardi, G. and Butterfield, R.: Modelling Ten Years Of Downhill Creep Data, Proc. XV ICSMFE, Istanbul, 1, 99-102, 2000.

Hohenemser, K. and Prager, W.: Fundamental equations and definitions concerning the mechanics of isotropic continua, J. Rheol., 3, 1932.

Hungr, O. and Morgenstern, N. R.: High velocity ring shear tests on sand, Géotechnique, 34, 415-421, 1984.

Iverson, R. M. and Major, J. J.: Rainfall groundwater flow and seasonal movements at Minor Creek Landslide, NW California: physical interpretation of empirical relations, Geol. Soc. Am. Bull., 99, 1987. 
Jaeger, J. C.: Elasticity, Fracture and Flow, John Wiley and Sons, 1964.

Leroueil, S., Vaunat, J., Picarelli, L., Locat, J., Lee, H., and Faure, R.: Geotechnical characterisation of slope movements, 7th Int. Symp. On Landslides, Trondheim, 1, 53-74, 1996.

Manfredini, G., Martinetti, S., Ribacchi, R., Santoro, V. M., Sciotti, M., and Silvestri, T.: An earthflow in the Sinni Valley (Italy), Proc. X Int. Conf. On Soil Mechanics and Foundation Engineering, Stocholm, vol. 3, pp. 457-462, 1981.

Maugeri, M., Motta, E., and Raciti, E.: Analisi dei movimenti di versante nella Sicilia Orientale: il caso di Gagliano Castelferrato - Conservazione del suolo 1974-2004 - CNR-GNDCI, 2004.

Maugeri, M., Motta, E., and Raciti, E.: Modelling slow slope movements driven by fluctuating ground water level, Proc. XI Int. Conf. of IACMAG, Prediction, Analysis and Design in Geomechanical Applications, Turin, Italy, 19-24 June 2005, vol. 3, pp. 569-576, 2005.

Maxwell, I.: On the Dynamical Theory of gases, Phil. Mag., (4), 35, 129, 135, 1868.

Morgenstern, N. R.: Geotechnical aspects of environmental control, Proc. XI Int. Conf. on Soil Mechanics and Foundation Engineering, San Francisco, vol. 1, pp. 155-185, 1985.

Nakamura, H.: Landslides in silts and sands mainly in Japan, Proc. IV Int. Symp. On Landslides, Toronto, 155-178, 1984.

Pellegrino, A., Ramondini, M., Russo, C., and Urciuoli, G.: Kinematic features of earthflows in Southern Italy, VIII Int. Symp. On Landslides, June 26-30, Cardiff, (3), 1195-1202, 2000.

Pellegrino, A. and Urciuoli, G.: Spostamenti di frane di colata in argille varicolori, IARG2002, June 19-21, Naples, 2002.

Picarelli, L.: Researches on slow slope movements carried out at the two universities of Naples, Italian Geotechnical Journal XXXI, 2, 37-48, 1997.

Piscitelli, F. and Urciuoli, G.: Regime delle pressioni neutre in frane di colata in argille varicolori, Proc. IARG 2001, Milan, May 10$11,2001$.
Pouget, P., Cartier, G., and Pilot, G.: Comportement De Remblais Construits Sur Versant Instable, Proc. XI International Conference On Soil Machanics And Foundation Engineering, San Francisco, vol. 4, pp. 2345-2348, 1985.

Raciti, E.: Interpretazione delle Caratteristiche Cinematiche dei Movimenti Lenti di Versante attraverso l'Analisi Numerica, PhD thesis, University of Catania, Italy, 2003.

Reiner, M.: Rheology, in: Handbuch der Physics, Band VI: Elastizitat und Plastizitat, edited by: Flugge, S., pp. 434-550, 1958.

Russo, C.: Caratteri Evolutivi Dei Movimenti Traslativi e Loro Interpretazione Meccanica Attraverso L'analisi Numerica, PhD thesis, University La Sapienza, Roma and University Federico II, Naples, 1997.

Russo, C. and Urciuoli, G.: Influenza della variazione di pressoni neuter sugli spostamenti di frane lente, Italian Geotechnical Journal XXXIII, 1, 71-76, 1999.

Sangrey, D. A., Harrop-Williams, K. O., and Klaiber, J. A.: Predicting ground-water response to precipitations, J. Geotech. Eng., ASCE, 110, n 7, pp. 957-975, 1984.

Sirangelo, B. and Versace, P.: Modelli stocastici di precipitazione e soglie pluviometriche di innesco dei movimenti franosi, Convegno di Idraulica e Costruzioni Idrauliche, Firenze 31 Agosto-4 Settembre, 1992.

Somigliana, C.: Sul coefficiente di attrito interno del ghiaccio e la determinazione della profondità dei ghiacciai, Bollettino del Comitato Glaciologico Italiano, No. 6, pp. 13-25, 1925.

Vulliet, L.: Modèlisation Des Pentes Naturelles En Mouvement Thése $\mathrm{N}^{\circ}$ 635, Ecole Polytechnique Fédérale De Lausanne, Suisse, 1986.

Vulliet, L.: Modelling Creeping Slopes, Italian Geotechnical Journal XXXIII, 1, 71-76, 1999.

Urciuoli, G.: Pore pressure in unstable slopes constituted by fissured clay shales, The Geotechnics of Hard Soils-Soft Rocks, October 11-14 Naples, (2), 1177-1185, 1998. 